\title{
Promoción del Turismo Cubano a través del uso de las tecnologías y prácticas de herramientas como la Storytelling
}

DOI: https://doi.org/10.33262/ap.v2i1.22

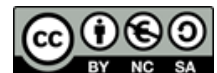

Promotion of Cuban Tourism through the use of technologies and tools practices such as Storytelling

Carolina Boari Caraciola., ${ }^{1}$ Dayana Vidal Diaz., ${ }^{2}$ Daniela Vidal Diaz., ${ }^{3} \&$ Juliana Maria Costa. $^{4}$

\begin{abstract}
.
Visiting Cuba is part of a unique history in the world, where resistance, survival, traces of the past and the search for openness to the future coexist in symbiosis. This article analyzes the promotion of Cuban tourism through the use of storytelling, with the aim of building a narrative that reinforces the glory and image of the leaders of the Cuban Revolution, making visitors participate in a tour, where the leaders of such a movement are the main characters and the inhabitants of the island, the secondary actors. The progressive opening of Cuba and the use of the internet have caused a new revolution in the country, the digital one, in charge of communicating to the world the tourist charms of the region, stimulating new businesses and attracting millions of visitors each year.
\end{abstract}

Keywords: Cuba, tourism, narration, digital revolution, Internet.

\footnotetext{
${ }^{1}$ Universidad Paulista (UNIP). São Paulo, Brasil.niria0101@gmail.com

${ }^{2}$ Universidad de Matanzas. La Habana, Cuba.niria0101@gmail.com

${ }^{3}$ Universidad de Matanzas. La Habana, Cuba.niria0101@gmail.com

${ }^{4}$ Universidad de São Paulo. São Paulo, Brasil. niria0101@gmail.com
} 


\section{Resumen.}

Visitar Cuba es parte de una historia única en el mundo, donde la resistencia, la supervivencia, las huellas del pasado y la búsqueda de la apertura hacia el futuro conviven en simbiosis. Este artículo analiza la promoción del turismo cubano a través del uso del storytelling, con el objetivo de construir una narrativa que refuerce la gloria y la imagen de los líderes de la Revolución Cubana, haciendo partícipes a los visitantes de un recorrido donde los líderes de tal movimiento son los personajes principales y, los habitantes de la isla, los actores secundarios. La progresiva apertura de Cuba y el uso de internet han provocado una nueva revolución en el país, la digital, encargada de comunicar al mundo los encantos turísticos de la región, estimular nuevos negocios y atraer a millones de visitantes cada año.

Palabras claves: Cuba, turismo, narración, revolución digital, Internet.

\section{Introducción.}

Caminar por La Habana es parte de una narrativa que cuenta glorias del pasado, con los rasgos de la época contemporánea. Niños jugando en la calle, coches clásicos de los años cincuenta en movimiento, parejas de enamorados al atardecer en el Malecón, la conservación de la tradición centenaria del canonazo de las nueve, el museo del ron, los colores y los ritmos cálidos son algunas de las experiencias inolvidables que la capital cubana proporciona. Los sitios de construcción de nuevos edificios contrastan con las casas con aspecto de ruinas, debido al desgaste del tiempo, que exhiben banderas del país, en sus balcones, y encantan a los turistas de los más diversos lugares, quienes aprecian un entorno exclusivo donde todo está rodeado de los mitos de la Revolución.

La Revolución Cubana triunfo en 1959 y sus huellas están absolutamente vivas en todos los espacios de la isla. La historia de Cuba debe y necesita ser analizada con detenimiento, sin embargo, es necesario dejar claro que nuestro objetivo, en este artículo, no es un estudio político o social en profundidad de la memoria cubana, sino una observación de cómo se desarrollaron y desarrollaron los hechos que son relevantes para la construcción y promoción del turismo cubano en la actualidad. Así, la reanudación de algunos datos anteriores y posteriores a la Revolución Cubana es necesaria para su comprensión, lo que justifica un breve relato de los momentos más significativos.

Cuba fue la última colonia de América Latina en liberarse de España, un proceso que duró unos treinta años. El movimiento independentista fue liderado por José Martí y apoyado por Estados Unidos. Además del interés geográfico, dado que la isla es "[...] una región estratégica para los intereses geopolíticos y económicos de USA [...]” (OLIVEIRA, 2015, p. 47), querían fortalecer las relaciones con Cuba, principalmente en relación con el comercio de azúcar, mineral de hierro y tabaco. Tras reconocer la independencia de Cuba, en el Tratado 
de París de 1898, España transfirió el control de Cuba a Estados Unidos, estableciendo un gobierno provisional encabezado por el general John R. Brooke.

La presencia norteamericana introduce diferentes elementos en el proceso independentista de Cuba en relación a otros movimientos latinoamericanos.

El tratamiento de la cuestión nacional involucra realidades propias de una forma de colonialismo retractor y de un nuevo imperialismo emergente que combina la expansión económica de los intereses privados nacionales con una política exterior intervencionista. (AYERBE, 2004, pág.25)

La independencia de Cuba estuvo condicionada a la Enmienda Platt, de 1902, preparada incluso antes de la Constitución cubana, y su existencia se explicaba por la necesidad de proteger la isla de posibles invasiones europeas, manteniéndola bajo el control de Estados Unidos. Durante los cuatro años de ocupación estadounidense, Cuba se fue organizando en la línea estadounidense en cuanto a los paradigmas de educación, costumbres, estilos de vida, "[...] pero principalmente, para modelar la economía cubana al modelo norteamericano [...]" (OLIVEIRA, 2015, p. 47). El país funcionaba como un "patio trasero" estadounidense, donde se liberaban todos los excesos, como la corrupción, el juego y la prostitución.

El primer presidente electo del país fue Tomás Estrada Palma, representante del Partido Revolucionario Cubano, fundado por Martí. Desde entonces, el país ha atravesado "un [...] período de ocho años de frágil democracia ... con las presidencias de Grau San Martín (19441948) y Prío Socarrás (1948-1952)" (AYERBE, 2004, pág.26). El 10 de marzo de 1952 Fulgêncio Batista lideró un golpe de Estado, apoyado por Estados Unidos, que culminó con una fuerte dictadura militar en el país. En ese momento surgió un "[...] movimiento de oposición cuyo desenvolvimiento inaugurará una nueva etapa en la historia política latinoamericana". (Ibíd. Pág. 28)

En Cuba estallaron movimientos de resistencia, con énfasis en la figura de Fidel Castro, quien en 1959, con el hermano Raúl y el amigo Che Guevara, lideró el movimiento que derrocó la dictadura [...] de Fulgêncio Batista [...]. Como primer ministro de la nueva república de Cuba, estableció un estado marxista-leninista de partido único. A pesar de los intentos estadounidenses de deponerlo o incluso asesinarlo, se convirtió en presidente en 1976 (KELLY et al, 2013, p. 339).

La Revolución Cubana obtuvo un fuerte apoyo de los sectores más pobres de la población y resultó en una serie de transformaciones en el país, con el objetivo de mejorar las condiciones de vida de las personas, fortalecer la industria, moralizar su imagen ante el mundo y, principalmente, reforma agraria, medida considerada la más radical. Además, hubo un fuerte compromiso por transformar la educación en el país "[...] en pocos meses el analfabetismo se ha reducido al nivel más bajo de América Latina, el 3,9\% de la población". (AYERBE, 2004, pág.68) 
Los revolucionarios llegaron al poder el 8 de enero de 1959. "Castro comenzó a desmantelar el dominio estadounidense sobre la economía, nacionalizando todas las fábricas sin ninguna compensación. En respuesta, Estados Unidos impuso un embargo comercial muy fuerte, por lo que Castro se dirigió a la URSS en busca de apoyo”. (WERNER, 2017, pág.309)

El embargo a Cuba continúa hoy, entendiéndose como "una orden de gobierno que interrumpe el comercio o cualquier actividad comercial con un país específico [...]" (Ibid., P. 342). El país se alió con la ex Unión Soviética, sin embargo, con la crisis en Europa del Este, Cuba perdió el “[...] respaldo político de la ex Unión Soviética; comienza el 'período especial en tiempos de paz', denominación del gobierno cubano para el nuevo contexto que enfrenta el país, considerado el más difícil desde 1959” (AYERBE, 2004, pág. 83)

La crisis cubana se intensificó y el gobierno de Fidel comenzó a perder popularidad. En respuesta, se llevó a cabo la reforma constitucional de 1992, que promovió una serie de cambios, como permitir el ingreso de fondos de cubanos residentes en el exterior, así como abrir pequeñas empresas privadas, liberar el dólar para uso en transacciones. asentamientos para la venta de parte de la producción agrícola por colonos en mercados públicos. En ese momento, el turismo se convirtió en la actividad más prestigiosa de la isla, con el objetivo de atraer inversiones y generar nuevos puestos de trabajo. Según AYERBE (Ibid., P. 85) en 1986, el número de turistas que visitaban la isla era de doscientos mil, pasando a un millón y medio en 1999 y a dos millones en 2003.

En 2006, Fidel Castro, gran líder de la Revolución Cubana, luego de sucesivos problemas de salud, dejó el poder, a la edad de 80 años, transfiriendo el gobierno a su hermano, Raúl. Fidel falleció el 25 de noviembre de 2016, dejando su legado e imagen como blanco de idolatría o severas críticas para el mundo entero.

Desde entonces, Cuba ha atravesado un proceso de reapertura, permitiendo una mayor participación del sector privado y la inversión de empresas extranjeras en todos los sectores empresariales. La gente puede comprar y vender bienes raíces, lo cual está prohibido desde la Revolución.

Desde 2013, Cuba vive una nueva revolución, la digital. Hasta este momento, Internet solo era utilizado por turistas, en hoteles, lo que convertía al país en el menos conectado de occidente. En 2018, hubo otro avance en materia de conectividad, internet se hizo disponible en los celulares y, según el presidente Miguel Díaz-Canel, sucesor de Raúl Castro, será el responsable del mayor impulso de la economía.

El uso de la tecnología ha transformado la comunicación en la isla, aunque el acceso está controlado por una empresa estatal, internet brinda nuevos negocios en el sector turístico cubano, que serán analizados a continuación. 


\section{Desarrollo.}

\section{La tecnología como herramienta poderosa para una nueva configuración turística en} Cuba.

Internet y sus diversas posibilidades hacen del desarrollo de la relación con el cliente un elemento fundamental para poder canalizar y difundir los mensajes que una empresa pretende trasmitir al público. Sin embargo, para que esto suceda, las marcas deben poder adaptarse a diferentes contextos.

En el sector turístico, que ha crecido significativamente en los últimos años, esto no es diferente, permitiendo a cada país ofrecer y promover sus recursos y, así, lograr ser conocido a nivel mundial, además de incrementar el número de visitantes, estimulando el consumo y mejorar su situación económica.

El surgimiento de las redes sociales ha fomentado el comportamiento de los consumidores para intercambiar experiencias, comparar y recomendar productos y servicios, hecho que puede ser explotado por las empresas, mediante el uso de testimonios positivos de los usuarios, para apalancar estrategias comerciales.

La influencia de las tecnologías de la información y la comunicación (TIC) en el sector turístico y, especialmente, en la comunicación de productos y en la gestión de las relaciones con el público es bastante eficiente. Según ROSALES (2018), las aplicaciones Web 2.0 basadas en opiniones y valoraciones de usuarios a escala global, específicamente TripAdvisor, influyen en las prácticas de relaciones públicas y comunicación turística, obligando a una gestión cuidadosa de la reputación online. Si, por un lado, los nuevos medios están disponibles para que las organizaciones se comuniquen con sus audiencias, por otro, también son una fuente de comentarios y evaluaciones directos que pueden reforzar positivamente la imagen de una organización o socavar su credibilidad con opiniones negativas que desafían a las nuevas prácticas de relaciones públicas.

Las redes sociales se convierten en una forma dinámica y amigable de promocionar o publicitar productos. Según el Estudio Anual de Redes Sociales 2019, el 55\% de los usuarios dijo que investigó en Facebook u otras redes sociales en busca de un producto antes de decidirse a comprarlo, lo que indica la importancia de mantener una buena imagen en estos medios.

El sector turístico cubano ha avanzado mucho con la apertura de internet en el país, en el que ha crecido interesantes prácticas para publicitar y posicionar empresas, estatales o privadas, que han utilizado la tecnología para crear experiencias positivas de sus productos y servicios, en un intento de llegar a los clientes y reconocimiento en distintas plataformas online, con énfasis en la publicidad en la aplicación de mensajería instantánea, WhatsApp. 
A medida que la informatización de la sociedad y las tecnologías de la información y la comunicación se disparan en Cuba, se abren una serie de oportunidades para establecer, mantener y mejorar las conexiones, tanto con clientes actuales como potenciales. En este sentido, Cuba ha implementado una avalancha de cambios desde la llegada de internet $3 \mathrm{G}$ y 4G a los celulares, aprovechando que más de 3.7 millones de usuarios acceden a internet en el país a través de la red móvil y, además, se contabilizan casi 1.600 áreas Wi-Fi y 1,7 millones de cuentas permanentes.

El turismo cubano se destaca del resto por ofrecer una serie de atractivos naturales, como las paradisíacas playas de Varadero, además de las cuestiones históricas y culturales que hacen del país un destino único.

Según datos del Ministerio de Turismo de Cuba, en 2019, el país registró un récord de visitantes extranjeros, con 4,2 millones de visitantes, un aumento del 16,2\% con respecto al año anterior, resultado notable si se observa. nivel mundial de movimiento turístico que creció solo un 4\%. Canadá es la principal fuente de turismo de la isla, seguida de los mercados europeos.

Según Mcdougall (1997), los viajes favorecen la producción de imágenes, que a su vez tienen grandes poderes en cuanto a metáfora, síntesis y sinestesia. El término topofilia acuñado por Yu Fu Tuan en 1980, asocia el sentimiento con el lugar, incluyendo los lazos emocionales de todos los seres humanos con el entorno material. Según el geógrafo, el entorno puede no ser la causa directa de la topofilia, pero proporciona el estímulo sensorial que, al actuar como imagen percibida, da forma a nuestras alegrías e ideales. "Los estímulos sensoriales son potencialmente infinitos: a lo que decidimos prestar atención (valor o amor) es un accidente del temperamento individual, propósito y fuerzas culturales que actúan en un momento dado". (TUAN, 1980, pág.129)

La gestión de las redes sociales en algunos hoteles y empresas no estatales del país se delega en empresas consultoras que se dedican a realizar rankings y estudios sobre cómo los hoteles interactúan en las plataformas sociales (SANCHIS, 2012).

El Community Manager es el profesional responsable de las comunidades de Internet en torno a un producto, marca o empresa. Cabe señalar que las comunidades son grupos de personas en el entorno virtual interconectados por intereses comunes.

El trabajo del Community Manager, a nivel mundial, es atraer, mantener y satisfacer las necesidades de esa comunidad en torno a la marca que representa.

Las tareas habituales de su actividad son las siguientes: buscar nuevas oportunidades virales para expandir las fronteras de la comunidad; identificar y analizar patrones y tendencias en las demandas de los miembros de la comunidad y en el comportamiento del servicio ofrecido por el hotel; crear y publicar contenido de alta calidad en diferentes canales; gestionar 
usuarios, así como analizar el comportamiento de la comunidad y, finalmente, elaborar informes de campaña, investigando diferentes formas de relacionarse con el cliente.

Desde sus inicios, la economía colaborativa o plataformas web P2P ha estado constituida por los distribuidores, por excelencia, de bed and breakfast. Los principales ejemplos de este tipo de sitios son: Homestay, HomeAway, Alterkeys, Only-Apartments, 9Flats, Wimdu y AirBnB, siendo este el más utilizado y destacado en Cuba en los últimos años, atrayendo una gran cantidad de clientes a hoteles y domicilios particulares. Estas plataformas están especializadas en poner en contacto a personas que ofrecen una casa, apartamento o habitación para reservar con potenciales viajeros.

Cuba tiene actualmente 70.000 habitaciones en más de 300 hoteles repartidos por todo el país y 2.000 habitaciones privadas como hostales y casas particulares.

El Ministerio de Turismo de Cuba reconoce y define los alojamientos turísticos no estatales. Según el MINTUR, los hospedajes no estatales son inmuebles ubicados en áreas de interés turístico o no, que brindan servicios de hospedaje en unidades habitacionales amobladas. Además, cuentan con servicios de salud privados o colectivos, que pueden o no ofrecer alimentos, lavandería y otros servicios legalmente autorizados. El número de turistas que se alojan en estos establecimientos no ha dejado de crecer.

Si a finales de 2004, según De Armas Sánchez (2009), 373.794 turistas optaron por el alojamiento no estatal, a finales de 2017, según datos del MINTUR, un total de 1.229.278 turistas prefirieron esta opción. Entre 1997 y 2017, dos momentos marcaron la evolución del número de turistas alojados en alojamientos no estatales. El primero ocurrió en 2011, con la apertura del autoempleo en el país. Desde ese año hasta 2014, el crecimiento medio anual fue del 12,91\%. Antes de 2011, el porcentaje de crecimiento anual era del 2,6\%; a pesar de años como 2008 y 2009, cuando el número disminuyó en un $-9,9 \%$ y $-9,62 \%$, respectivamente. El segundo momento tuvo lugar en abril de 2015, con el inicio de operaciones, en Cuba, de la plataforma norteamericana AirBnB.

Airbnb, la plataforma de economía colaborativa más utilizada en el mundo, es el resultado de la explosión del comercio electrónico y las agencias de viajes online en los últimos años, su presencia mundial como nuevo modelo de negocio en relación a los canales de distribución existentes, ha permitido un gran posicionamiento. En Cuba, es utilizado por proveedores de alojamiento no estatales para distribuir su oferta. Si bien el Ministerio de Trabajo ha renovado las licencias para el alquiler de habitaciones y casas, aún no existe una regulación relacionada con la aplicación, lo que dificulta su desarrollo, siendo utilizada, en la isla, por proveedores de hospedaje no estatales para la distribución de su oferta.

Esta plataforma no es la única que funciona con hosting no estatal. Para propietarios cubanos, que solo alquilan habitaciones, se recomienda utilizar Homestay, 9Flats y Wimdu y para propietarios que alquilan casas completas se recomienda utilizar Only-Apartments. 
El objetivo de esta alianza entre el sector estatal y el alojamiento privado es diversificar el producto turístico cubano a partir de la complementariedad de ofertas, en un entorno en el que ninguno de los actores perjudica al otro, contribuyendo ambas partes a la construcción simbólica del destino Cuba y rescatar los valores identitarios de cada región (LAVANDERA \& VILLA, 2015).

Los empresarios autónomos, incluidos los que se encuentran en alojamientos no estatales, tienen derecho a la formación gratuita en los centros FORMATUR, en disciplinas turísticas básicas, además de pagar por cursos de formación especializada, tales como: animación turística, lengua extranjera, contabilidad aplicada al turismo y elementos de costos y técnicas de guía. En cuanto a la vivienda no estatal, según el Ministerio de Trabajo y Previsión Social de Cuba, la Plaza de la Revolución es el lugar de la capital que cuenta con la mayor cantidad de habitaciones de este tipo, de las cuales 2.605, lo que representa 29,6\% del total existente en La Habana, con el mayor número de trabajadores no estatales inscritos en la actividad de ama de llaves en la modalidad CUC, con 814 propietarios.

Hasta el momento hemos analizado la parte operativa del turismo en Cuba, destacando el uso de internet como herramienta vital para su desarrollo y crecimiento. Examinaremos ahora cómo el turismo en la isla está rodeado de símbolos para su fortalecimiento, anclado en la figura. de los líderes de la Revolución Cubana, que se han convertido en verdaderos mitos. La historia se enseña desde temprana edad en las escuelas, los rostros de sus personajes principales están por todas partes, imprimen los más diversos productos comerciales, desde camisetas, hasta postales e imanes de nevera. El turismo de la isla se desarrolla y se consolida al contar esta historia, que llena de orgullo al país. (AYERBE, 2004, pág.64)

\section{Los mitos de la Revolución como protagonistas principales de la promoción del turismo cubano.}

El orgullo cívico es a menudo lo que da etiquetas a las ciudades, y su reputación se basa en una imagen notable. La conciencia del pasado es un elemento importante que justifica el amor por el lugar, y la retórica patriótica siempre ha enfatizado las raíces de un pueblo. Para intensificar la lealtad, el proceso de contar la historia del lugar, a través de monumentos en el paisaje, es un mecanismo interesante que intensifica la memoria de batallas pasadas, lo que corrobora la creencia de que la sangre de los héroes santificó la tierra. Las postales, por ejemplo, promueven la imaginabilidad, estando especializadas en difundir el valor de las principales calles de un lugar, edificios, monumentos y el simbolismo de determinadas personalidades.

La valoración del entorno por parte del visitante es esencialmente estética. El turista juzga por apariencia, por algún criterio formal de belleza. Es necesario un esfuerzo especial para fomentar la empatía en relación con la vida y los valores de los habitantes. 
En nuestra sociedad de alta movilidad, el visitante y el nativo se centran en aspectos muy diferentes del entorno. Las impresiones fugaces de las personas que pasan por allí no pueden pasarse por alto. En general, se puede decir que el visitante (y en especial el turista) tiene un punto de vista que muchas veces se reduce a usar sus ojos para componer cuadros, el nativo, según Tuan (1980), tiene una actitud compleja derivada de su inmersión en la totalidad de su entorno. Por otro lado, tal actitud del indígena solo puede expresarse con dificultad e indirectamente a través del comportamiento, la tradición local, el conocimiento y el mito. (ibíd, p. 73)

La promoción del turismo cubano se ancla en la práctica del Storytelling, haciendo partícipes al visitante de un viaje, donde los mitos de la Revolución son los protagonistas principales y los habitantes de la isla, los actores secundarios.

Hay autores que defienden la teoría del Storytelling como la rienda necesaria para mantener el orden social. Es por eso que las fábulas tienen lecciones como "no te fíes de los extraños" y todas las mitologías cuentan profecías sobre personas que están llegando a dominar y para las que debes estar preparado. Este tipo de mando se hizo en forma de historia porque, en estos casos, son los detalles los que marcan la diferencia entre ganar y morir. (PALACIOS y TERENZZO, 2016, p. 48)

En este sentido, es cierto que la narrativa contada debe ser excepcional, inolvidable y capaz de establecer conexiones simbólicas, conteniendo "[...] personajes, objetivos, conflictos y vívidos escenarios sensoriales”. (LUPTON, 2020, pág.21)

Los líderes de la Revolución Cubana se convirtieron en mitos en su territorio, pues además de derrocar la dictadura de Fulgencio Batista, lograron mantener una política antiimperialista y socialista hasta la época contemporánea, enfrentándose a las más diversas represalias. Aunque la definición de mito varía según la ciencia que lo estudia, podemos entenderlo, en este contexto, de acuerdo con el aspecto historicista, que considera al mito como "[...] una representación de episodios reales del pasado [...]”. (SILVA y SILVA, 2013, p. 294)

La Revolución Cubana contó con la participación de grandes nombres, como Camilo Cienfuegos, Ramiro Valdés Menéndez, Juan Almeida Bosque, Frank País, José Antonio Echeverría, sin embargo, el protagonismo y protagonismo de las imágenes de Ernesto Guevara y Fidel Castro es innegable.

Ernesto Guevara (1928 - 1967), también conocido por su apodo Che, que significa amigo, fue un médico argentino que se hizo ciudadano cubano en 1959. Reconocido como un hombre de acción, adoptó prácticas guerrilleras en sus acciones tácticas, él lo que resultó en "[...] una enorme contribución al desarrollo del socialismo revolucionario" (KELLY et al, 2013, p. 312). El Che creía que el éxito de la Revolución Cubana se debía a la movilización popular y estuvo a la vanguardia de la economía del país durante los años 1959 y 1965, fue titular del Departamento de Industrias del Instituto Nacional de Reforma Agraria, director 
del Banco Nacional de Cuba y ministro Industria. En 1965 salió de Cuba para luchar en la guerrilla del Congo y, más tarde, en Bolivia, donde fue capturado y ejecutado. Según la revista Time, se le considera "[...] uno de los cien personajes más famosos del siglo XX".

La frase "Hasta la victoria, siempre", atribuida al Che, está inscrita en su pared, ubicada en la Plaza de la Revolución, en La Habana, siendo una de las más populares de la izquierda mundial, reproducida en canciones, postales, calles de la ciudad, así como en souvenirs de la isla.

Fidel Castro (1926 - 2016), “[...] figura representativa de la política antiimperialista [...]” (KELLY et al, 2013, p. 339) era hijo de un rico agricultor, estudió derecho en la Universidad de La Habana, época en la que se involucró con la política cubana. Luchó en rebeliones contra gobiernos de derecha en Colombia y República Dominicana, además de liderar movimientos de resistencia contra la dictadura de Fulgêncio Batista. Abogó por medidas relacionadas con la reforma agraria, cambios en el sistema educativo, así como la nacionalización de empresas proveedoras de servicios públicos, especialmente en las áreas de telefonía y electricidad. Ocupó el cargo de primer ministro del país entre 1959 y 1976 y fue presidente entre los años 1976 y 2008. Castro fue el encargado de transformar Cuba en un estado socialista, promover la nacionalización de las industrias extranjeras, incentivar la producción nacional y la institución. de un solo partido. Fidel proclamó largos discursos y, en uno, proclamó una de sus frases más famosas: "Condenadme, no importa. La historia me absolverá".

Además de líderes de la Revolución Cubana, el Che y Fidel pueden compararse a héroes. La palabra héroe se define de la siguiente manera, según el diccionario de la lengua portuguesa: "aquel que se distingue por su valor o por sus acciones extraordinarias, principalmente por hechos brillantes durante la guerra. [...] El que es condecorado por sus acciones valientes, por su carácter magnánimo, por su comportamiento altruista”. El héroe se mueve entre el mundo cotidiano y el especial, posicionándose en el imaginario colectivo como un protector, una figura singular y culta, que muchas veces puede ser considerado un santo salvador.

Trascendiendo la imagen política, se puede decir que el Che y Fidel se convirtieron en celebridades que avalan el consumo y el turismo cubano, es decir, personalidades del más alto reconocimiento público, que utilizan este prestigio para trasladar sus principales características, como el amor a la patria, el heroísmo, la lucha en nombre del pueblo, la valentía, el coraje, los productos que se venden en la isla, los recorridos realizados e incluso la experiencia que se lleva del lugar. Visitar Cuba es parte de una historia única en el mundo, donde la resistencia, la supervivencia, las huellas del pasado y la búsqueda de la apertura hacia el futuro conviven en simbiosis.

El argumento es que el proceso de aprobación depende de las propiedades simbólicas de la celebridad que respalda. Utilizando una perspectiva de "transferencia de significado", se muestra que estas propiedades pertenecen a la celebridad y luego se transfieren de la 
celebridad al bien de consumo y del bien de consumo al consumidor. (McCRACKEN, 2012, pág.109)

Los principales productos que se comercializan en la isla son el ron y el puro, verdaderos símbolos de Cuba, consecuencia de la alta producción de azúcar y tabaco, siendo las marcas más prestigiosas, incluso a nivel mundial, Havana Club y Cohiba. Las referidas marcas llevan en su constitución características como calidad, historia, origen, tradición, siendo avaladas por los líderes de la Revolución. Fidel fue embajador de los puros producidos en la isla, y la marca Cohiba fue creada en exclusiva para él a principios de los años sesenta, comenzando a comercializarse al público a partir de 1982.

El ron, patrimonio nacional de Cuba, está presente en la creación de dos reconocidas bebidas cubanas, el mojito y el daiquiri, que adquirieron fama internacional gracias al escritor estadounidense Ernest Hemingway, quien vivió veinte años en la isla, siendo responsable de la frase "mi mojito en La Bodeguita, mi daiquiri en La Floridita", bares que atraen a turistas de todos partes deseosos de probar este tipo de bebidas.

La importancia del ron en Cuba es tan fuerte que hay un museo en su honor, mantenido por la marca Havana Club, que presenta en su logo trazos que hacen referencia a su lugar de origen, como el lema "El ron de Cuba" y la imagen de la Giraldilla, una estatua del siglo XVII, uno de los símbolos más representativos de la ciudad de La Habana.

El turismo en la capital cubana brinda sensaciones únicas. El paisaje circundante tiene una rica experiencia sinestésica, donde los ritmos de salsa y mambo se mezclan con el sonido de los más diversos idiomas de los turistas extranjeros.

Los colores de las casas, de los carros viejos, de la ropa de los indígenas transmiten calidez y receptividad y el aroma de las comidas típicas invita al visitante a degustar nuevos sabores. La Habana no exhibe carteles, vallas publicitarias o mobiliario urbano publicitario de productos de consumo, sin embargo, la actividad publicitaria tiene como objetivo promover el sistema político, el gobierno, mediante el uso de imágenes de los líderes de la Revolución, frases emblemáticas os símbolos referentes al país.

Fig.1 presenta una recopilación de imágenes de La Habana, destacando la bandera del país, las más prestigiosas marcas de productos cubanos, ron Havana Club y puros Cohiba, autos antiguos, calles de la ciudad, la inscripción del nombre de Fidel Castro y su imagen insertada en la bandera cubana en las paredes de La Guarida, el bar La Floridita, así como el busto del escritor Ernest Hemingway, la imagen del Che y su célebre frase en la Plaza de la Revolución y el Capitolio de Cuba. 
Figura 1. Collage de recorrido por La Habana. Fuente: Archivo personal.
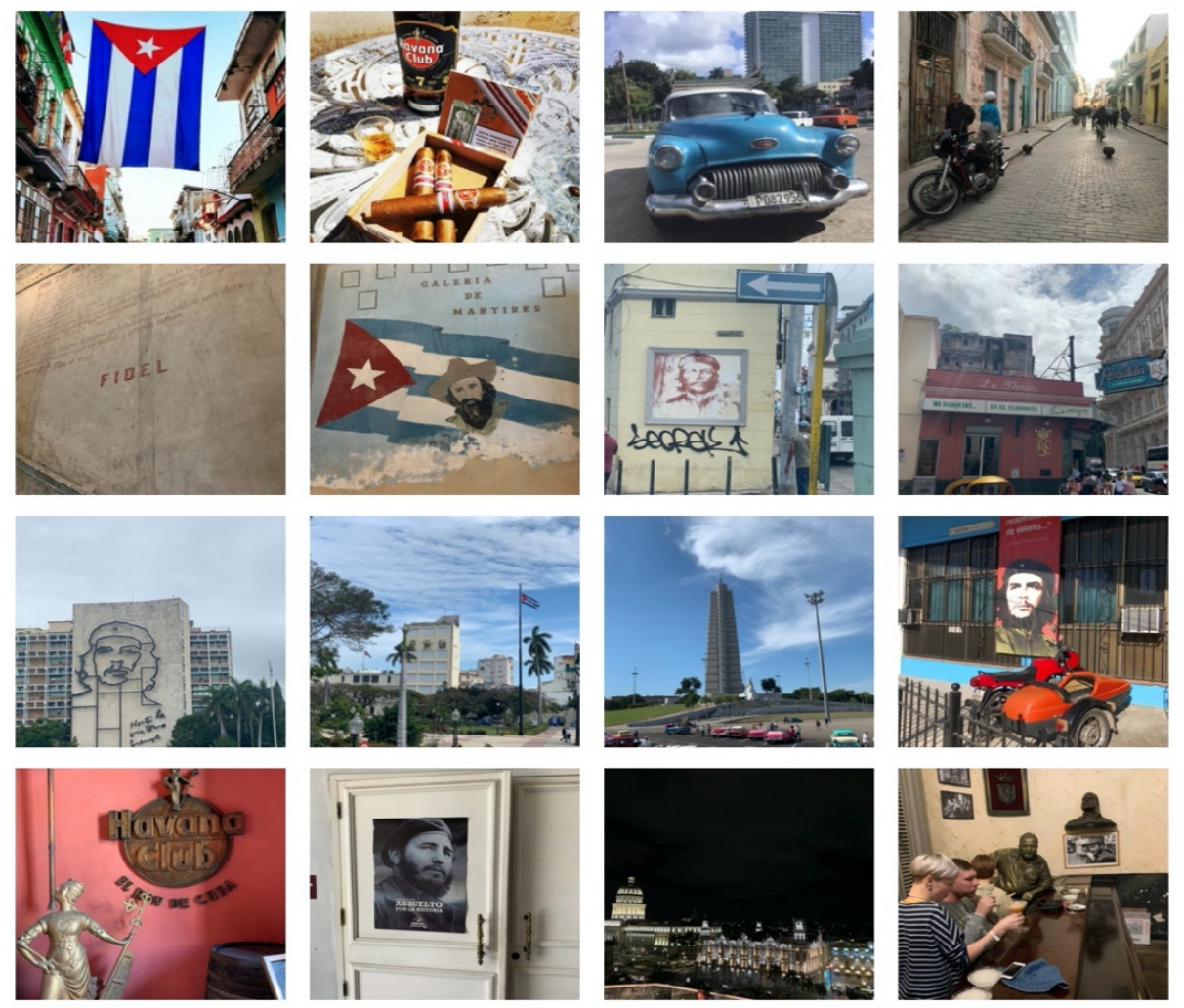

Fuente: Elaboración propia.

Caminando por las calles de La Habana, los turistas se dan cuenta del reconocimiento a los logros alcanzados por los líderes de la Revolución, así como del amor y respeto del pueblo cubano por su patria, a través del despliegue de banderas en los balcones de las casas, en lugares públicos, en monumentos y en los principales puntos turísticos. Cada bandera representa la identidad de un pueblo y el cubano, conocido como la Estrella Solitaria, tiene los siguientes elementos en su constitución: tres franjas horizontales de color azul, "[...] que representan la división geográfica de la colonia de Cuba [...]" en la década de 1950, correspondiente al oeste, centro y este; separados por dos bandas en blanco, que simbolizan "[...] la pureza de todos los patriotas cubanos y las intenciones del movimiento independentista popular".

El triángulo equilátero, que "[...] evoca libertad, igualdad y fraternidad, ideales revolucionarios de fuerte ascendencia para el pueblo cubano", es de color rojo, que "[...] simboliza la sangre que habría que derramar para lograr la liberación". Finalmente, hay una estrella blanca, solitaria, insertada en el triángulo, que expresa "[...] solidaridad absoluta entre los pueblos", con "sus cinco puntas que significan fuerza, belleza, sabiduría, virtud y solidaridad". La estrella de cinco puntas es uno de los ideogramas más utilizados en las banderas de los países occidentales, siendo "[...] ampliamente utilizada como símbolo militar 
y de aplicación de la ley. Denota la estrella de Belém, usada para indicar una calidad superior" (O'CONNELL y AIREY, 2010, p. 232). La idea de superioridad también se ve reforzada por el triángulo equilátero, ya que se utiliza como "[...] símbolo de poder, éxito, prosperidad y seguridad". (Ibíd., P. 266)

\section{Conclusiones.}

- El turismo de Cuba aprovecha la historia del país para su promoción, contando en cada parte de su territorio, en sus monumentos, en los principales lugares de visita, destacando una narrativa llena de hazañas de lucha y resistencia, pero también con la ambición de construir un futuro de apertura, modernidad e inclusión en el escenario mundial, sin perder su identidad. Mucho más que un viaje, el turismo cubano brinda un encuentro con un mundo que ya no existe, congelado en los años cincuenta, y una realidad a punto de estallar, claramente percibida en cada obra de edificios en construcción.

\section{Referencias bibliográficas.}

AYERBE, L. F. (2004). A Revolução Cubana. São Paulo, Brasil: Editora Unesp.

CAMPBELL, J. (1989). O herói de mil faces. São Paulo, Brasil: Cultrix. trad: Adail Ubirajara Sobral.

CASAQUI, V. (2014). Publicidade. In: MARCONDES, Ciro Filho (Org.). Dicionário da comunicação. $2^{\mathrm{a}}$ ed., rev. e ampl. São Paulo, Brasil: Paulus

FUENTES, N. (2017). A autobiografia de Fidel Castro. Rio de Janeiro, Brasil: LeYa. Trad. Luis Reyes Gil.

KELLY, P. et. al. (2013). O livro da política. São Paulo, Brasil: Globo. Trad. Rafael Longo.

LUPTON, E. (2020). O design como storytelling. São Paulo, Brasil: Gustavo Gili. Trad. Mariana Bandarra.

MCCRACKEN, G. (2012). Cultura \& consumo II: mercados, significados e gerenciamento de marcas. Rio de Janeiro, Brasil: MAUAD. Trad. Ana Carolina Balthazar.

MCDOUGALL, W. A. (1997). Promised land, crusader state: The American Encounter with the World Since 1776. Boston. Estados Unidos: Houghton Mifflin.

O’CONNELL, M. y AIREY, R. (2011). Almanaque ilustrado dos símbolos. São Paulo, Brasil: Editora Escala Ltda. Tradução de Débora Ginza.

OLIVEIRA, L. O. de (s.f). O imperialismo estadunidense na América Latina e Caribe no final do Século XIX: a questão de Cuba através do Tratado de Paz de Paris e da Emenda Platt. Disponible en: https://www.lume.ufrgs.br/bitstream/handle/10183/132370/000983637.pdf?sequenc $\mathrm{e}=1$

PALACIOS, F. y TERENZZO, M. (2016). O guia completo do Storytelling. Rio de Janeiro, Brasil: Alta Books. 
ROSALES, A. V. (s.f). Tendencias del consumidor digital para el producto turístico. Disponible en: https://revistas.udg.co.cu/index.php/redel/article/view/136.

SANCHIS, S. C. (s.f). La comunicación y las redes sociales. Disponible en:https://www.3ciencias.com/wpcontent/uploads/2013/01/comunicacion-y-redessociales.pdf

SILVA, K. V. y SILVA, M. H. (2013). Dicionário de conceitos históricos. São Paulo, Brasil: Contexto.

TUAN, Y. F. (1980). Topofilia: um estudo da percepção, atitudes e valores do meio ambiente. São Paulo, Brsail: DIFEL.

WERNER, C. (2017). O livro da história. São Paulo, Brasil: GloboLivros. Trad. Rafael Longo. 


\section{Para citar el artículo indexado}

Boari Caraciola, C., Vidal Diaz, D., Vidal Diaz, D., \& Costa, J. M. (2020). Promoción del Turismo Cubano a través del uso de las tecnologías y prácticas de herramientas como la Storytelling. AlfaPublicaciones, 2(1), 56-70. https://doi.org/10.33262/ap.v2i1.22

\section{【 Ciencia}

El artículo que se publica es de exclusiva responsabilidad de los autores y no necesariamente reflejan el pensamiento de la Revista Alpha Publicaciones.

El artículo queda en propiedad de la revista y, por tanto, su publicación parcial y/o total en otro medio tiene que ser autorizado por el director de la Revista Alpha Publicaciones.
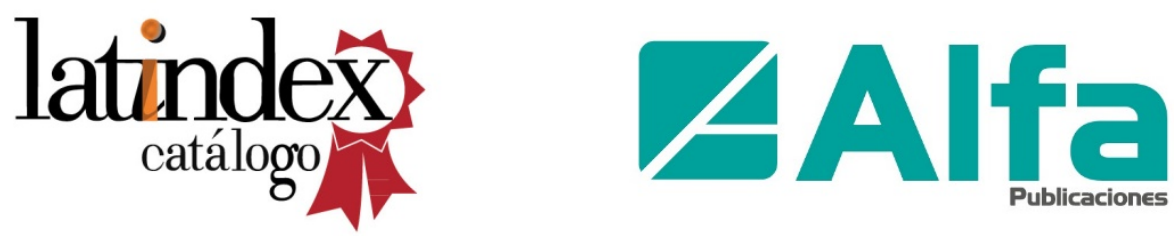